\title{
Algorithm of Maximizing the Set of Common Solutions for Several MCDM Problems and it's Application for Security Personnel Scheduling
}

\author{
S. Dadelo, A. Krylovas, N. Kosareva, E.K. Zavadskas, R. Dadeliene
}

\author{
Stanislav Dadelo, Aleksandras Krylovas, \\ Natalja Kosareva*, Edmundas Kazimieras Zavadskas \\ Vilnius Gediminas Technical University \\ Sauletekio al. 11, LT-10223 Vilnius, Lithuania \\ E-mail: stanislav.dadelo@vgtu.lt, aleksandras.krylovas@vgtu.lt, \\ natalja.kosareva@vgtu.lt, edmundas.zavadskas@vgtu.lt \\ *Corresponding author: natalja.kosareva@vgtu.lt
}

\section{Ruta Dadeliene}

Lithuanian University of Educational Sciences

Studentu st. 39, LT-08106 Vilnius, Lithuania

E-mail: ruta.dadeliene@leu.lt

\begin{abstract}
The article deals with the task of elite selection of private security personnel on the basis of objective and subjective criteria. One of the possible solutions of this multiple criteria decision making (MCDM) problem is creation of heuristics allowing to minimize discrepancy of ranks calculated for the objective and subjective criteria on the basis of the best security staff. The proposed heuristic combines interval points re-selection and random points generation methods. Two optimizing algorithms are proposed. It is shown how this method is applied for solving specific task of elite selection from security personnel.
\end{abstract}

Keywords: preference feature, multiple criteria decision making, heuristics, optimizing algorithm.

\section{Introduction}

EU private security sector employs millions of people and this figure is constantly growing [1]. Economic trends provide further development of the private security. It is predicted that over the next 10 years, the U.S. private security sector job demand will increase by $15 \%$ and this is much higher growth rate compared to the overall job growth around the U.S. economy [2]. Safety business formed specific personnel management challenges. Personnel selection and placement to the necessary positions (ranking) is seen as the most important factor affecting the organizations security, stability and development [3] and for private security this process takes on a deeper meaning. Personnel selection process focuses on measurement and evaluation of specific potential, skills and personal characteristics of candidates. Security personnel evaluation process requires identification of specific characteristics (criteria) for the occupation of the post and their weights determination [4]. It is necessary to develop universal algorithms for personnel selection [5]. Developed selection and evaluation systems are mainly focused on companies operating cost reduction, in order to optimize staffing requirements and layout planning [6], but is not enough in the safety field. Assessing the activities of private security, their complexity and the peculiarities of the hazard, the following complexity - hazard levels are distinguished: 1) protection of civil objects; 2) protection of critical and strategic objects, collection, and personal protection [7]. Evolution of the modern world generated the demand of private security services in military operations. However, armed security services in the "hot" spots of the world providing companies are often confronted with the staff inappropriate behavior in dangerous and emergency situations. Assessing the private security business diversity, personnel evaluation and selection procedure 
for different tasks becomes necessity. There is a need to look for factors affecting the security staff competence and professional activities as a basis for generation of algorithms for employees evaluation and selection for different tasks procedures [8]. Evaluating of personnel engaged in security features in dangerous environment it is necessary to search for specific solutions [3]. Critical tasks in hazardous environments, which may result in loss of health and even life, must carry only the elite guards. Ryan et al. [9] note that only about $10-12 \%$ of the total sample of candidates are able to meet the demands posed by members of special elite forces. Dessler [10] states that only $15 \%$ of the total sample of individuals can be evaluated in the maximum. Recent research reveals the elite diagnostic possibilities according to six sigma principle [11]. Private security personnel selection process should point competency assessment in two directions: external (evaluation of subordinate by his immediate superior) and internal (personal competence) [12]. Relevance of the problem occurs in the construction of selection algorithms for private security elite, capable of effectively carry out extremely important and dangerous tasks. This scientific problem is not paid enough attention. The aim of this study is construction approval of private security elite selection algorithm. A similar kind of research has not yet been done.

An overview of possible MCDM methods for this problem solution is provided by Zavadskas and Turskis [13]. Recently fuzzy MCDM methods are becoming increasingly popular [14]. In this article heuristic methods, based on the function, minimizing non-compliance of ranks, calculated for the best security staff in accordance with objective and subjective criteria are proposed.

\section{Internal and external evaluation criteria}

Participants. One hundred and eighteen security guards were randomly selected from the company G4S Lietuva; twenty two leader managers (experts) of G4S Lietuva with not less than 10 years of service at private security structures involving execution and organization of security ranked the competences chosen by authors of the article.

Security guards internal evaluation $(x)$ (objective testing, measuring, personal competence). Selected security guards were tested and evaluated according to 41 criteria. The data received were classified into six groups of competences (variables) regarding the features analysed [12] (Table 1):

1. Theoretical and practical preparation $\left(x_{1}\right)$ : knowledge, skills, abilities, practical experience - acquired throughout life;

2. Professional activity $\left(x_{2}\right)$ : carrying out required tasks;

3. Mental qualities $\left(x_{3}\right)$ : individual psychical qualities vital for performance of professional activities;

4. Physical development $\left(x_{4}\right)$ : morphological indications of a body;

5. Motor abilities $\left(x_{5}\right)$ : personal physical conditions allowing carrying out physical tasks at work or home, during leisure, and reflecting the level of physical qualities;

6. Fighting efficiency $\left(x_{6}\right)$ : a set of physical and mental qualities influencing the ability to effectively carry out actions fighting an adversary in direct contact.

Table1: Security guards internal evaluation criteria (objective tests and measurements) 


\begin{tabular}{|c|c|c|c|c|c|c|}
\hline \multirow{2}{*}{ Security guards } & \multicolumn{7}{|c|}{ Criteria (competences) } \\
\cline { 2 - 7 } & $x_{1}$ & $x_{2}$ & $x_{3}$ & $x_{4}$ & $x_{5}$ & $x_{6}$ \\
\hline max (highest values) & 2.582 & 2.186 & 2.651 & 3.388 & 2.768 & 1.696 \\
\hline min (lowest values) & -1.606 & -2.567 & -2.518 & -1.948 & -2.596 & -1.709 \\
\hline$a_{1}$ & 1.358 & -1.503 & 0.607 & 0.520 & 1.381 & 1.696 \\
\hline$a_{2}$ & 0.259 & -0.549 & -0.424 & -1.487 & -0.645 & 0.068 \\
\hline$a_{3}$ & -0.984 & 0.465 & 0.101 & -0.479 & 0.690 & -0.100 \\
\hline$\vdots$ & $\vdots$ & $\vdots$ & $\vdots$ & $\vdots$ & $\vdots$ & $\vdots$ \\
\hline$a_{116}$ & 0.225 & -0.500 & -0.837 & -0.599 & 0.749 & 0.795 \\
\hline$a_{117}$ & 0.561 & -1.366 & 0.438 & -0.017 & 0.013 & -0.903 \\
\hline$a_{118}$ & -1.512 & -1.391 & -2.180 & -1.666 & -1.520 & -0.845 \\
\hline
\end{tabular}

Security guards external evaluation $(y)$ (evaluation of subordinate by his immediate superior). Team leaders evaluated their subordinates based on A. Sakalas [15] modified methodology (Table 2). They have been assessed on nine criteria that could affect security guards professional competences:

1. Specialty knowledge, professionalism $\left(y_{1}\right)$ : versatility, knowledge about their and related occupations;

2. Diligence and positive attitude to work $\left(y_{2}\right)$ : activeness, responsibility, discipline, zeal, vocation to work;

3. Behaviour with colleagues and supervisors $\left(y_{3}\right)$ : the ability to cooperate and work in a team;

4. Reliability at work $\left(y_{4}\right)$ : ability and willingness to perform tasks independently;

5. Quality of work $\left(y_{5}\right)$ : the ability to avoid mistakes;

6. Workload performance $\left(y_{6}\right)$ : the ability to carry out the maximum amount of work;

7. Image $\left(y_{7}\right)$ : the self-representational skills (exterior, posture, language culture);

8. Development rate $\left(y_{8}\right)$ : the ability to quickly adapt to new requirements and new working conditions;

9. Being promissing $\left(y_{9}\right)$ : potential for career.

Table 2: Security guards external evaluation criteria (evaluation of subordinate by his immediate superior)

\begin{tabular}{|c|c|c|c|c|c|c|c|c|c|}
\hline \multirow{2}{*}{ Security guards } & \multicolumn{10}{|c|}{ Criteria (competences) } \\
\cline { 2 - 11 } & $y_{1}$ & $y_{2}$ & $y_{3}$ & $y_{4}$ & $y_{5}$ & $y_{6}$ & $y_{7}$ & $y_{8}$ & $y_{9}$ \\
\hline max (highest values) & 5 & 5 & 5 & 5 & 5 & 5 & 5 & 5 & 5 \\
\hline min (lowest values) & 0 & 0 & 0 & 0 & 0 & 0 & 0 & 0 & 0 \\
\hline$a_{1}$ & 3 & 4 & 4 & 4 & 4 & 4 & 4 & 4 & 4 \\
\hline$a_{2}$ & 4 & 4 & 4 & 4 & 5 & 3 & 3 & 4 & 4 \\
\hline$a_{3}$ & 3 & 4 & 4 & 4 & 4 & 4 & 4 & 4 & 4 \\
\hline$\vdots$ & $\vdots$ & $\vdots$ & $\vdots$ & $\vdots$ & $\vdots$ & $\vdots$ & $\vdots$ & $\vdots$ & $\vdots$ \\
\hline$a_{116}$ & 2 & 3 & 3 & 4 & 3 & 3 & 3 & 3 & 2 \\
\hline$a_{117}$ & 1 & 2 & 2 & 2 & 2 & 3 & 2 & 1 & 1 \\
\hline$a_{118}$ & 3 & 3 & 4 & 3 & 3 & 3 & 3 & 3 & 2 \\
\hline
\end{tabular}

Security staff competency assessment is depicted in Figure 1.

\section{Mathematical model}

Definition. Suppose that vector of real components $X=\left(x_{1}, x_{2}, \ldots, x_{n}\right),(\forall j) x_{j} \geqslant 0$, has the meaning of some measurable values and is the set of $n$ criteria values. Any function 


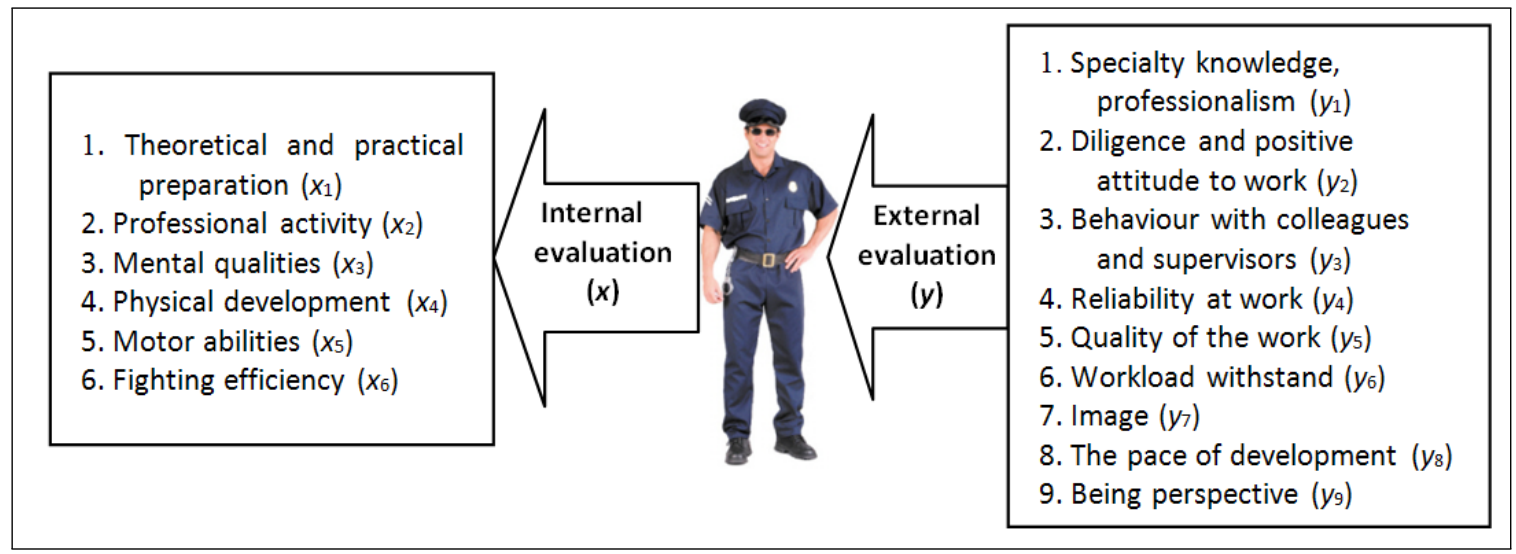

Figure 1: Research progress

$\varphi: R^{n} \rightarrow R$ will be called criteria convolution, if it nondecreasing for each variable, i. e.

$$
(\forall j=1,2, \ldots n, \forall \delta>0) \varphi\left(\ldots, x_{j}+\delta, \ldots\right) \geqslant \varphi\left(\ldots, x_{j}, \ldots\right) .
$$

Note, that if for the two alternatives $X^{(1)}$ and $X^{(2)}$ the Pareto dominance is valid $X^{(1)} \succ X^{(2)}$ $\left(\forall j=1,2, \ldots n: x_{j}^{(1)} \geqslant x_{j}^{(2)}\right.$ and $\left.\exists i: x_{i}^{(1)}>x_{i}^{(2)}\right)$, then inequality (1) will be true for the criteria convolution: $\varphi\left(X^{(1)}\right) \geqslant \varphi\left(X^{(2)}\right)$.

Suppose, that permutation $\left(j_{1}, j_{2}, \ldots, j_{n}\right)$ of natural numbers $\{1,2, \ldots, n\}$ determine the criterion $X$ components $x_{j}$ preferences $x_{j_{1}} \succ x_{j_{2}} \succ \cdots \succ x_{j_{n}}$. For example, permutation $(2,3,1)$ means that the most important influence has the second component of criterion $X=\left(x_{1}, x_{2}, x_{3}\right)$, and the least influence has the first component.

Definition. Let's say that criteria convolution $\varphi$ has preferences feature $\left(j_{1}, j_{2}, \ldots, j_{n}\right)$, if all the inequalities are valid:

$$
(\forall i<k \& \delta>0) \varphi\left(\ldots, x_{i}+\delta, \ldots, x_{k}, \ldots\right) \geqslant \varphi\left(\ldots, x_{i}, \ldots, x_{k}+\delta, \ldots\right)
$$

when $j_{i}>j_{k}$.

Note, that criteria convolutions determined on the basis of weighted averages have preferences feature defined by (2). For example, criteria convolution

$$
\varphi(X)=\frac{w_{1} x_{1}+w_{2} x_{2}+w_{3} x_{3}+w_{4} x_{4}}{w_{1}+w_{2}+w_{3}+w_{4}}
$$

when $w_{2}>w_{3}>w_{1}>w_{4}>0$ has preferences feature $(2,3,1,4)$.

Convolution

$$
\varphi(X)=x_{1}^{p_{1}} x_{2}^{p_{2}} x_{3}^{p_{3}}
$$

when $p_{2}>p_{1}>p_{3}>0$ has preferences feature $(2,1,3)$.

\subsection{Formulation of optimization problems}

Suppose that for the certain alternatives criteria-referenced evaluations are known $X^{(k)}=$ $\left(x_{1}^{(k)}, x_{2}^{(k)}, \ldots, x_{n}^{(k)}\right), Y^{(k)}=\left(y_{1}^{(k)}, y_{2}^{(k)}, \ldots, y_{m}^{(k)}\right), k=1,2, \ldots, K$ and criteria $X, Y$ preferences are determined: $\left(j_{1}, j_{2}, \ldots, j_{n}\right),\left(i_{1}, i_{2}, \ldots, i_{m}\right)$.

Suppose that $\varphi$ and $\psi$ are convolutions of criteria $X$ and $Y$ respectively, having corresponding preferences features. For each alternative $\left(X^{(k)}, Y^{(k)}\right)$ values of both criteria convolutions 
$\varphi\left(X^{(k)}\right)$ and $\psi\left(Y^{(k)}\right)$ are calculated and numbered in ascending order to obtain ranks of alternatives: $r_{x}^{(k)}, r_{y}^{(k)}$. Note that the lower is the rank, the better is alternative.

Let's denote $A_{K_{x}}$ and $B_{K_{y}}$ sets of the best alternatives - those subsets of the set $\{1,2, \ldots, K\}$ whose items ranks $r_{x}^{(k)}<K_{x}$ and $r_{y}^{(k)}<K_{y}$ respectively. Here $K_{x}, K_{y}$ mean the proportion of the best alternatives to be selected (generally $10-15 \%$, i. e. $K_{x}, K_{y} \in[0.10 K, 0.15 K]$ ).

Denote $\mathcal{S}_{\left(j_{1}, j_{2}, \ldots, j_{n}\right)}$ class of convolutions having preferences feature $\left(j_{1}, j_{2}, \ldots, j_{n}\right)$. In this class of functions we'll search for the function $\varphi$ (analogously $\psi$ ). Denote $\left|A_{K_{x}} \cap B_{K_{y}}\right|$ number of elements in intersection of sets $A_{K_{x}}$ and $B_{K_{y}}$ and formulate the optimization problem:

$$
\begin{aligned}
& \max _{\varphi \in \mathcal{S}_{\left(j_{1}, j_{2}, \ldots, j_{n}\right)}}\left|A_{K_{x}} \cap B_{K_{y}}\right| . \\
& \psi \in \mathcal{S}_{\left(i_{1}, i_{2}, \ldots, i_{m}\right)}
\end{aligned}
$$

Notice that if $K_{x}=K_{y}=K$ the problem (3) has trivial solution

$$
A_{K_{x}} \cap B_{K_{y}}=\{1,2, \ldots, K\}
$$

for any convolutions $\varphi, \psi$. Decreasing values of parameters $K_{x}, K_{y}$ imply the decreasing number of common elements (intersection) of the sets $A_{K_{x}}, B_{K_{y}}$. If this number is less than necessary, we mus increase values of parameters $K_{x}, K_{y}$. This means that criteria $X$ and $Y$ don't match. Choose the numbers $K_{x}^{\prime} \leqslant K_{x}, K_{y}^{\prime} \leqslant K_{y}$. The incompatibility of criteria $X$ and $Y$ is quantitatively described by number of all elements of the union of sets $A_{K_{x}^{\prime}}$ and $B_{K_{y}^{\prime}}$ which don't belong to the intersection in the right side of formula (3), i. e. the alternatives with high rank according to the one and low rank according to another criterion. So the problem (3) could be supplemented with additional one

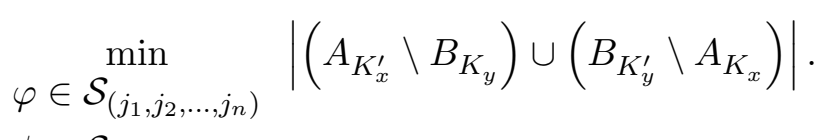

$$
\begin{aligned}
& \psi \in \mathcal{S}_{\left(i_{1}, i_{2}, \ldots, i_{m}\right)}
\end{aligned}
$$

Notice that the problem (4) also has trivial solution $A_{K_{x}^{\prime}} \cup B_{K_{y}^{\prime}}=\varnothing$, if $K_{x}^{\prime}=K_{y}^{\prime}=1$. In general, this means a certain amount of "fine" for the ignorance of dubious alternatives and numbers $K_{x}^{\prime} \leqslant K_{x}, K_{y}^{\prime} \leqslant K_{y}$ must to be the larger.

\subsection{Restrictions and general scheme of the research}

Formulated optimization problems (3) and (4) aren't easy. Construction of the effective algorithms for their solving is interesting, but poorly investigated issue. Efficiency of these algorithms should strongly depend on the class of criteria convolutions $\mathcal{S}_{\left(j_{1}, j_{2}, \ldots, j_{n}\right)}$. In this article we restrict our investigation with the functions from the class of the weighted averages:

$$
\varphi_{\left(j_{1}, j_{2}, \ldots, j_{n}\right)}\left(x_{1}, x_{2}, \ldots, x_{n}\right)=\frac{\sum_{i=1}^{n} w_{j_{i}} x_{j_{i}}}{\sum_{i=1}^{n} w_{i}} .
$$

here $w_{j_{1}} \geqslant w_{j_{2}} \geqslant \cdots \geqslant w_{j_{n}} \geqslant 0$.

Preferences feature $\left(j_{1}, j_{2}, \ldots, j_{n}\right)$ is determined by experts estimates of the form $x_{j_{1}} \succ x_{j_{2}} \succ$ $\cdots \succ x_{j_{n}}$. In this article we limit ourselves to calculation of the average estimates for criteria ranks and numbering of $x_{j}$ accordingly. There are many various ranking methods and their comparison will be our further investigation. 


\subsection{Solving the personnel selection problem (case study)}

The particular managerial task is solved in the paper. It requires finding an acceptable alternative sets having a clear and easily verifiable interpretation of the subject matter. Therefore, the comparison of solutions received by various methods could be their interesting practical suitability criteria and have a long-term value.

Task parameters are as follows:

the number of alternatives (security personnel compared with each other) $-K=118$; the number of vector criterion $X$ components (physical measurements of emploees) $n=6$; the number of vector criterion $Y$ components (managers assessment) $m=9$.

Criteria $X$ and $Y$ components priority was determined from expert estimates. Each of 22 experts had to specify priority permutations $x_{j_{1}} \succ x_{j_{2}} \succ \cdots \succ x_{j_{n}}$ and $y_{i_{1}} \succ y_{i_{2}} \succ \cdots \succ y_{i_{m}}$. These evaluations are shown in the Table 3:

Table 3: Criteria $X$ and $Y$ components ranks

\begin{tabular}{|c|c|c|c|c|c|c|c|c|c|c|c|c|c|c|c|}
\hline Expert & $x_{1}$ & $x_{2}$ & $x_{3}$ & $x_{4}$ & $x_{5}$ & $x_{6}$ & $y_{1}$ & $y_{2}$ & $y_{3}$ & $y_{4}$ & $y_{5}$ & $y_{6}$ & $y_{7}$ & $y_{8}$ & $y_{9}$ \\
\hline 1 & 6 & 1 & 5 & 3 & 2 & 4 & 7 & 9 & 4 & 8 & 5 & 3 & 6 & 2 & 1 \\
\hline 2 & 5 & 2 & 3 & 1 & 6 & 4 & 7 & 9 & 5 & 6 & 8 & 2 & 3 & 4 & 1 \\
\hline 3 & 5 & 1 & 3 & 2 & 6 & 4 & 5 & 9 & 4 & 6 & 8 & 1 & 7 & 3 & 2 \\
\hline 4 & 6 & 1 & 5 & 3 & 4 & 2 & 5 & 9 & 7 & 8 & 6 & 3 & 4 & 2 & 1 \\
\hline 5 & 6 & 1 & 5 & 2 & 3 & 4 & 7 & 9 & 6 & 8 & 5 & 3 & 4 & 2 & 1 \\
\hline 6 & 5 & 1 & 4 & 2 & 6 & 3 & 5 & 9 & 6 & 8 & 7 & 3 & 4 & 2 & 1 \\
\hline 7 & 4 & 2 & 3 & 1 & 6 & 5 & 4 & 8 & 5 & 9 & 7 & 2 & 6 & 3 & 1 \\
\hline 8 & 6 & 2 & 5 & 3 & 4 & 1 & 6 & 8 & 5 & 9 & 7 & 3 & 4 & 2 & 1 \\
\hline 9 & 5 & 4 & 6 & 3 & 2 & 1 & 7 & 9 & 4 & 8 & 6 & 3 & 5 & 1 & 2 \\
\hline 10 & 5 & 4 & 6 & 1 & 2 & 3 & 6 & 7 & 4 & 9 & 8 & 3 & 5 & 2 & 1 \\
\hline 11 & 4 & 1 & 3 & 2 & 6 & 5 & 5 & 8 & 6 & 9 & 7 & 2 & 4 & 3 & 1 \\
\hline 12 & 6 & 2 & 4 & 1 & 5 & 3 & 6 & 9 & 5 & 7 & 8 & 4 & 3 & 2 & 1 \\
\hline 13 & 6 & 4 & 5 & 1 & 3 & 2 & 5 & 9 & 6 & 8 & 7 & 3 & 4 & 2 & 1 \\
\hline 14 & 6 & 3 & 5 & 1 & 4 & 2 & 7 & 8 & 6 & 9 & 5 & 4 & 3 & 2 & 1 \\
\hline 15 & 4 & 1 & 3 & 2 & 6 & 5 & 5 & 9 & 7 & 8 & 6 & 3 & 2 & 4 & 1 \\
\hline 16 & 4 & 1 & 3 & 2 & 6 & 5 & 7 & 9 & 8 & 6 & 5 & 4 & 2 & 3 & 1 \\
\hline 17 & 6 & 1 & 4 & 2 & 3 & 5 & 6 & 8 & 7 & 9 & 4 & 5 & 2 & 3 & 1 \\
\hline 18 & 6 & 3 & 4 & 1 & 5 & 2 & 6 & 9 & 8 & 7 & 4 & 5 & 2 & 3 & 1 \\
\hline 19 & 4 & 1 & 5 & 2 & 6 & 3 & 4 & 9 & 8 & 6 & 7 & 1 & 5 & 3 & 2 \\
\hline 20 & 6 & 2 & 4 & 1 & 5 & 3 & 5 & 9 & 6 & 7 & 8 & 3 & 4 & 2 & 1 \\
\hline 21 & 5 & 2 & 6 & 3 & 4 & 1 & 6 & 8 & 7 & 9 & 5 & 4 & 3 & 2 & 1 \\
\hline 22 & 4 & 1 & 6 & 3 & 2 & 5 & 6 & 9 & 7 & 8 & 5 & 4 & 2 & 3 & 1 \\
\hline$\Sigma$ & 114 & 41 & 97 & 42 & 96 & 72 & 127 & 190 & 131 & 172 & 138 & 68 & 84 & 55 & 25 \\
\hline$\overline{r_{i}}$ & 5.18 & 1.86 & 4.41 & 1.91 & 4.36 & 3.27 & 5.77 & 8.64 & 5.96 & 7.82 & 6.27 & 3.09 & 3.82 & 2.50 & 1.14 \\
\hline rank & 1 & 6 & 2 & 5 & 3 & 4 & 5 & 1 & 4 & 2 & 3 & 7 & 6 & 8 & 9 \\
\hline prefs & \multicolumn{6}{|c|}{$X:(1,3,5,6,4,2)$} & \multicolumn{9}{|c|}{$Y:(2,4,5,3,1,7,6,8,9)$} \\
\hline
\end{tabular}

Component's $X$ and $Y$ ranks preferences were calculated by method of sum (average) of ranks (i. e. the average place of each component was calculated and preferences drawn up.

\subsection{Optimization algorithm}

The heuristic is used for solving problem (3). Functions $\varphi(X)$ and $\psi(Y)$ will be selected from the class of functions (5) as follows:

$$
\varphi(X)=\alpha_{1} x_{1}+\alpha_{3} x_{3}+\alpha_{5} x_{5}+\alpha_{6} x_{6}+\alpha_{4} x_{4}+\alpha_{2} x_{2}, \alpha_{1} \geqslant \alpha_{3} \geqslant \alpha_{5} \geqslant \alpha_{6} \geqslant \alpha_{4} \geqslant \alpha_{2}>0,
$$


by analogy accordingly to the preference feature given in the last row of Table 3 :

$$
\psi(Y)=\beta_{2} y_{2}+\beta_{4} y_{4}+\cdots+\beta_{9} y_{9}, \beta_{2} \geqslant \beta_{4} \geqslant \beta_{5} \geqslant \cdots \geqslant \beta_{8} \geqslant \beta_{9}>0 .
$$

Weighted coefficients $\alpha_{j}$ and $\beta_{i}$ are determined so as to satisfy the normalizing condition

$$
\alpha_{1}+\cdots+\alpha_{6}=\beta_{1}+\cdots+\beta_{9}=1 .
$$

Designate $R^{(k)}(\alpha)$ and $R^{(k)}(\beta), k=1,2, \ldots, K$ ranks of numbers $\left\{\varphi\left(X^{(1)}\right), \varphi\left(X^{(2)}\right), \ldots, \varphi\left(X^{(K)}\right)\right\}$ and $\left\{\psi\left(Y^{(1)}\right), \psi\left(Y^{(2)}\right), \ldots, \psi\left(Y^{(K)}\right)\right\}(K=118)$.

Determine function of ranks discrepancies, i. e. sum of squares of highest ranks differences according to criteria $X$ and $Y$ :

$$
C R_{K_{x}, K_{y}}(\alpha, \beta)=\sum_{\substack{k \in\{1,2, \ldots, 118\}: \\ R^{(k)}(\alpha) \leqslant K_{x} \& R^{(k)}(\beta) \leqslant K_{y}}}\left(R^{(k)}(\alpha)-R^{(k)}(\beta)\right)^{2}
$$

and minimize this function

$$
\begin{aligned}
& \min _{\varphi \in \mathcal{S}_{\left(j_{1}, j_{2}, \ldots, j_{n}\right)}} C R_{K_{x}, K_{y}}(\alpha, \beta) . \\
& \psi \in \mathcal{S}_{\left(i_{1}, i_{2}, \ldots, i_{m}\right)}
\end{aligned}
$$

Here $K_{x}$ and $K_{y}$ are chosen so as $\left|A_{K_{x}} \cap B_{K_{y}}\right|=12$, since the goal is to select the top 12 security guards.

Minimization problem (8) is solved by re-selecting of values $\alpha_{j}, \beta_{i}$. For the search of values $\alpha_{1}$, $\alpha_{3}, \alpha_{5}$ and $\beta_{2}, \beta_{4}, \beta_{5}$ evenly divide intervals:

$$
\begin{gathered}
\alpha_{1} \in\left[\frac{1}{6}, 1\right), \alpha_{3} \in\left[\frac{1-\alpha_{1}}{5}, \min \left\{\alpha_{1}, 1-\alpha_{1}\right\}\right), \alpha_{5} \in\left[\frac{1-\alpha_{1}-\alpha_{3}}{4}, \min \left\{\alpha_{3}, 1-\alpha_{1}-\alpha_{3}\right\}\right), \\
\beta_{2} \in\left[\frac{1}{9}, 1\right), \beta_{4} \in\left[\frac{1-\beta_{2}}{8}, \min \left\{\beta_{2}, 1-\beta_{2}\right\}\right), \beta_{5} \in\left[\frac{1-\beta_{2}-\beta_{4}}{7}, \min \left\{\beta_{4}, 1-\beta_{2}-\beta_{4}\right\}\right) .
\end{gathered}
$$

Values $\alpha_{6}, \alpha_{4}, \beta_{3}, \beta_{1}, \beta_{7}, \beta_{6}, \beta_{8}$ are chosen randomly in the intervals constructed analogously. For example, $\alpha_{4}$ is uniformly distributed in the interval

$$
\alpha_{4} \in\left[\frac{1-\alpha_{1}-\alpha_{3}-\alpha_{5}-\alpha_{6}}{2}, \min \left\{\alpha_{6}, 1-\alpha_{1}-\alpha_{3}-\alpha_{5}-\alpha_{6}\right\}\right) .
$$

The remaining values $\alpha_{2}$ and $\beta_{9}$ are determined from the normalizing condition (6).

General scheme of the research is represented in Figure 2.

\section{Results and Discussion}

This heuristic enabled to achieve the criterion (8) value $C R_{12,12}(\alpha, \beta)=429$ with the following values of weights:

\begin{tabular}{|c|c|c|c|c|c|c|c|c|}
\hline$\alpha_{1}$ & $\alpha_{3}$ & $\alpha_{5}$ & $\alpha_{6}$ & $\alpha_{4}$ & $\alpha_{2}$ & \multicolumn{4}{|l|}{} \\
\hline 0.31 & 0.19 & 0.17 & 0.17 & 0.12 & 0.04 & \multicolumn{3}{|c|}{} \\
\hline \hline$\beta_{2}$ & $\beta_{4}$ & $\beta_{5}$ & $\beta_{3}$ & $\beta_{1}$ & $\beta_{7}$ & $\beta_{6}$ & $\beta_{8}$ & $\beta_{9}$ \\
\hline 0.41 & 0.24 & 0.08 & 0.08 & 0.06 & 0.05 & 0.03 & 0.03 & 0.02 \\
\hline
\end{tabular}




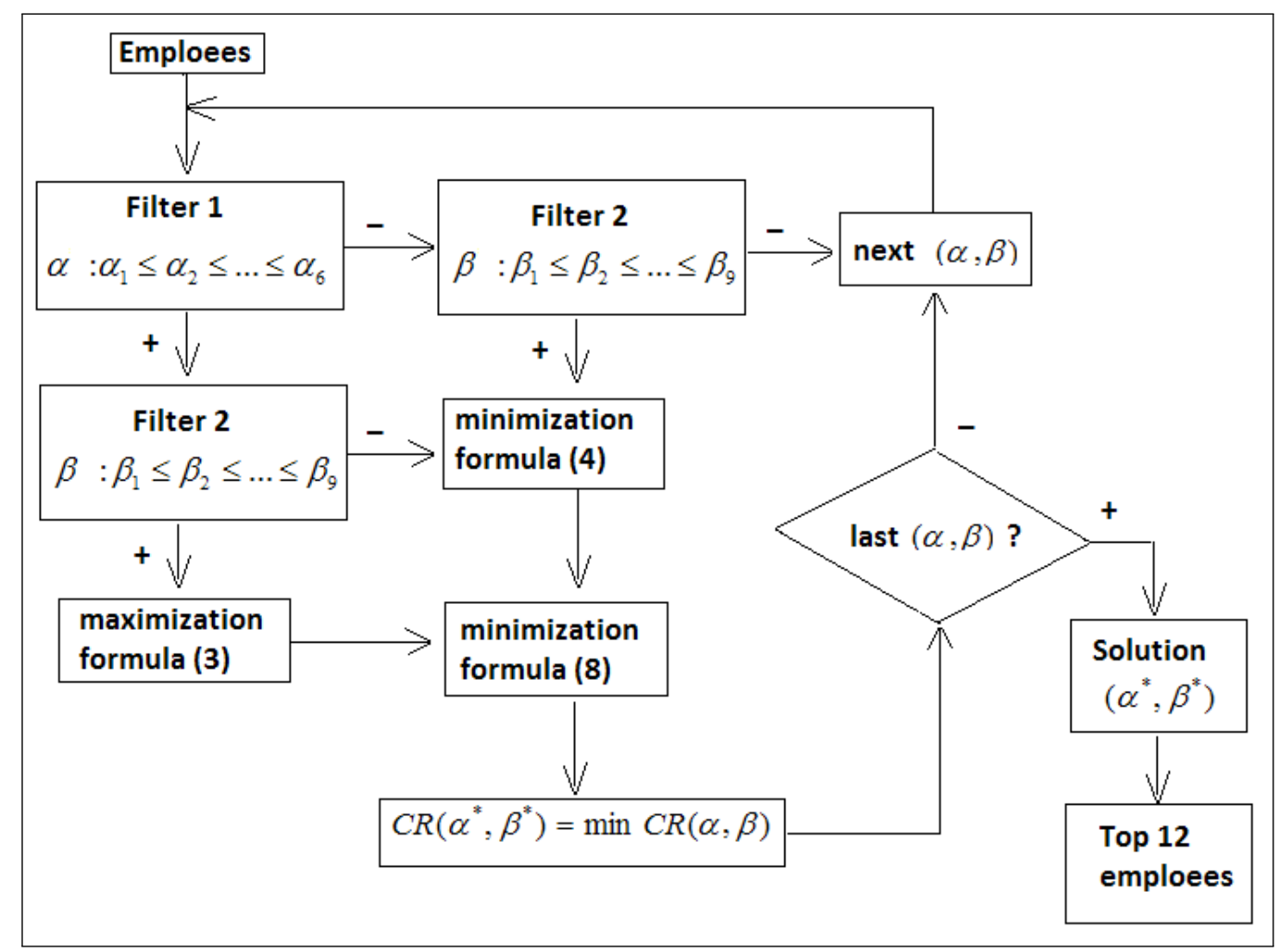

Figure 2: Research progress

Top 12 security guards are those belonging to the intersection $A_{K_{x}} \cap B_{K_{y}}$ : $a_{21}, a_{34}, a_{36}, a_{47}, a_{56}, a_{76}, a_{77}, a_{81}, a_{91}, a_{102}, a_{106}, a_{112}$.

According to another heuristics we are looking for such convolutions among all $\varphi \in \mathcal{S}_{\left(j_{1}, j_{2}, \ldots, j_{n}\right)}$ and $\psi \in \mathcal{S}_{\left(i_{1}, i_{2}, \ldots, i_{m}\right)}$ which maximize (3) and minimize (4). Since there are many solutions of problem (3)-(4), among the entire sample of solutions we are looking for one that minimize the sum (7). Let's choose $K_{x}^{\prime}=K_{y}^{\prime}=4$. Then we reached even lower criterion (8) value $C R_{12,12}(\alpha, \beta)=406$ and the following $X$ and $Y$ weights were obtained:

\begin{tabular}{|c|c|c|c|c|c|c|c|c|}
\hline$\alpha_{1}$ & $\alpha_{3}$ & $\alpha_{5}$ & $\alpha_{6}$ & $\alpha_{4}$ & $\alpha_{2}$ & \multicolumn{3}{|c|}{} \\
\hline 0.26 & 0.18 & 0.18 & 0.17 & 0.13 & 0.08 & \multicolumn{3}{|c}{} \\
\hline \hline$\beta_{2}$ & $\beta_{4}$ & $\beta_{5}$ & $\beta_{3}$ & $\beta_{1}$ & $\beta_{7}$ & $\beta_{6}$ & $\beta_{8}$ & $\beta_{9}$ \\
\hline 0.21 & 0.12 & 0.12 & 0.12 & 0.10 & 0.10 & 0.09 & 0.07 & 0.07 \\
\hline
\end{tabular}

Top 12 security guards were selected:

$a_{21}, a_{34}, a_{36}, a_{47}, a_{56}, a_{76}, a_{77}, a_{81}, a_{91}, a_{102}, a_{106}, a_{111}$. This solution differs from the first solution by only one employee - in place of $a_{112}$ is an employee $a_{111}$. Another 4 security guards were distinguished having high rank $(\geqslant 4)$ by one and low rank by another criterion: $a_{6}, a_{26}$, $a_{46}, a_{54}$.

Attention is drawn to the fact that future studies are interesting for the aspect of development of general design of the study for the similar problems, since a very different assessments have similar structure. Briefly this scheme can be described as follows. The same objects are independently characterized by several vector criteria (in this paper there are two, but the methodology is easily generalized for greater number of vector criteria). Vector components significance is not the same and significance hierarchy $\left(j_{1}, j_{2}, \ldots, j_{n}\right)$ is known (usually from the expert esti- 
mates). The proposed methodology allows the construction of the alternatives evaluation criteria by application of general design of the study and using all the existing information.

\section{Bibliography}

[1] van Dijk, J. (2008); The world of crime. Los Angeles, CA: Sage Publications.

[2] Bureau of Justice Statistics. (2008); Census of state and federal correctional federal correctional facilities, 2005. Washington, DC: Office of Justice Programs, U.S. Department of Justice.

[3] Garland B.; Hogan N.L.; Kelley T.; Kim B.; Lambert E.G. (2013); To Be or Not to Be Committed: The Effects of Continuance and Affective Commitment on Absenteeism and Turnover Intent among Private Prison Personnel. Journal of Applied Security Research, 8(1). $65-88$.

[4] Dadelo, S.; Turskis, Z.; Zavadskas, E. K.; Dadeliene, R. (2012); Multiple criteria assessment of elite security personal on the basis of aras and expert methods. Journal of economic computation and economic cybernetics studies and research, 46(4). 65-88.

[5] Brucker P.; Qu R.; Burke E. (2011); Personnel scheduling: Models and complexity. European Journal of Operational Research, 210. 467-473.

[6] van den Bergh J.; Belien J.; De Bruecker P.; Demeulemeester E.; De Boeck L. (2013); Personnel scheduling: A literature review. European Journal of Operational Research, 226. 367-385.

[7] Carlos M. (2011); A survey of the European security market. Economics of Security Working Paper 43, Berlin: Economics of Security.

[8] Dadelo, S.; Turskis, Z.; Zavadskas, E. K.; Dadeliene, R. (2013); Integrated multi-criteria decision making model based on wisdom-of-crowds principle for selection of the group of elite security guards. Archives of Budo, 9(2). 135-147.

[9] Ryan, M.; Mann, C.; Stilwell, A. (2003); The Encyclopedia of the World's Special Forces: Tactics, history, strategy, weapons. Amber Books Ltd., London.

[10] Dessler, G. (1999); Essentials of Human Resource Management, Upper Saddle River, NJ: Prentice Hall, 298.

[11] Suresh S.; Antony J.; Kumar M.; Douglas A. (2012); Six Sigma and leadership: some observations and agenda for future research, The TQM Journal, 24(3). 231-247.

[12] Dadelo, S. (2005); Czynniki determinujce kompetencjae pracownikow ochrony na Litwie. AWF Warszawa-Vilnius, 2005 [in Polish, abstract in English, in Lithuanian]

[13] Zavadskas, E. K.; Turskis, Z. (2011); Multiple criteria decision making (MCDM) methods in economics: an overview, Technological and Economic Development of Economy, 17(2). $397-427$.

[14] Kosareva, N.; Krylovas, A. (2013); Comparison of accuracy in ranking alternatives performing generalized fuzzy average functions, Technological and Economic Development of Economy, 19(1). 162-187.

[15] Sakalas, A. (2003); Personnel management. Vilnius: Margi rastai. [in Lithuanian] 